\title{
Investigation of Heat Transfer Characteristics of a Hierarchical Manifold Microchannel Heat Sink
}

\author{
Wenyuan Xie, Xiaochen Lv, Wei Yao, and Long $\mathrm{Li}^{*}$ \\ Qian Xuesen Laboratory of Space Technology, China Academy of Space Technology \\ NO. 104 Youyi Road, Haidian District, Beijing 100094, China \\ xiewenyuan@qxslab.cn; lvxiaochen@qxslab.cn; yaowei@qxslab.cn; lilong@qxslab.cn
}

\begin{abstract}
As the size of electronic components decreases and the performance of integrated circuits (ICs) improves, the heat flux generated also increase drastically, which brings a huge challenge to the traditional thermal management solutions. In recent years, the manifold microchannel heat sink has attracted intensive attentions due to its high heat dissipation performance and small hydraulic loss. In this paper, A series of $3 \times 3$ array of microchannel heat sinks with different aspect ratio are fabricated on a $1 \mathrm{~cm} \times 1 \mathrm{~cm}$ silicon chip using MEMS technology. The effects of inlet flow rate, channel depth and working fluid on the single-phase flow and heat transfer characteristics of the hierarchical manifold microchannel heat sink arrays are investigated via numerical and experimental methods.
\end{abstract}

Keywords: Heat transfer coefficient; Pressure drop; Single-phase flow; MEMS; COMSOL

\section{Introduction}

With the rapid development of micro-/nanoscale fabrication technology and the improvement of the integration of electronic components, the heat flux generated by the electronic components increases rapidly as its performance improves. These high-performance electronic components are widely used in mobile devices, electronic computers, spacecraft control systems and communication systems, and high-power lasers and detectors. The reliability problem caused by high heat flux has become the main factor restricting the development of electronic components [1], [2]. Compared with conventional heat sinks, microchannel heat sinks have better cooling capacity due to their large specific surface area, and have attracted extensive attention from researchers in recent years.

In 1981, Tuckerman and Pease completed the first experimental work on microchannel heat sinks. The results demonstrated an heat dissipation capacity as high as $7.9 \mathrm{MW} / \mathrm{m}^{2}$ with a temperature rise less than $71 \mathrm{~K}$, which opens the study of superior cooling devices based on the microchannel heat sinks at small or micro scale [1], [3]-[5]. In 1991, Harpole and Eninger proposed the concept of a manifold microchannel heat sinks, the heat dissipation performance was greatly improved while the pressure drop was reduced [2]. In addition, experimental results from Kim and Chun showed that the heat transfer performance of the manifold microchannel heat sink could be improved by $30 \%$ compared to the conventional microchannel devices [6]. Escher et al. found through experimental studies that there was a $70 \%$ difference in mass flow among the channels and proposed that the use of tapered flow channels can significantly reduce the problem of uneven flow distribution [7]. To optimize the flow field and heat transfer characteristics, Andhare et al. designed and processed a manifold microchannel heat sink that can work in counter flow and obtained better performance[8].

This paper completes the design and fabrication of the hierarchical manifold microchannel heat sink array. A $3 \times 3$ microchannel heat sink array is fabricated on a $1 \mathrm{~cm} \times 10 \mathrm{~cm}$ silicon chip. The length of the microchannel is $3000 \mu \mathrm{m}$, the width is $40 \mu \mathrm{m}$, and the depth is 40,150 , and $300 \mu \mathrm{m}$, respectively. The manifold structure reduces the flow length of the microchannel and improves its heat transfer capability and reduces its flow resistance. On-chip electronics cooling greatly reduces the contact thermal resistance between the chip and the heat sink. In this paper, the pressure drop, heat transfer coefficient and effective thermal resistance of the microchannel heat sink are studied through finite element simulation and experiment. 


\section{Experimental methods}

Figure 1 is the schematic diagram of the cooling chip. The heat sink is composed of multiple micro-channel heat sinks. The structure of a single microchannel heat sink is shown in the dashed part of Figure 1. Each microchannel heat sink consists of a microchannel layer and an on-chip manifold layer. The microchannel layer includes a silicon substrate and a set of parallel fins built on the substrate. The on-chip manifold layer defines the microchannel inlet and outlet. As shown in Figure 1, the fluid flows from the manifold layer, then the flow direction changes when the fluid hits the channel bottom wall, moves along the length to both ends of the channel and flows out from the outlets. The heaters and RTD were fabricated on the back of the silicon substrate, opposite to the microchannel structure to simulate heat input and measure the chip temperature. In this paper, we have designed and fabricated multiple sets of cooling chips with different geometrical dimension. The size of the cooling chip is $10 \mathrm{~mm} \times 10 \mathrm{~mm}$, the length of a single microchannel is $3000 \mu \mathrm{m}$, the width is $40 \mu \mathrm{m}$, and the depth is $40 \mu \mathrm{m}, 150 \mu \mathrm{m}$ and $300 \mu \mathrm{m}$, respectively, microchannel heat sinks form a $3 \times 3$ array.

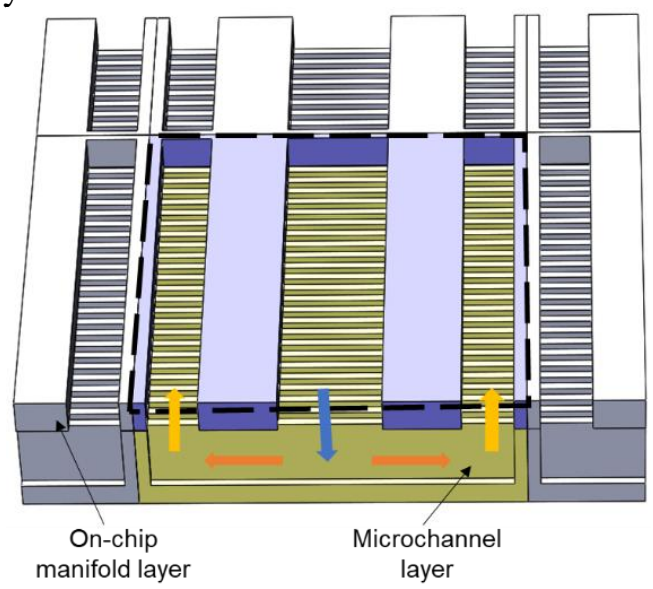

Fig. 1: Schematic diagram of manifold microchannel heat sink array.

The test device is shown in Figure 2. The system consists of a manifold base, a gasket, a hierarchical manifold distributor, a cooling chip, and a printed circuit board (PCB). The manifold base acts as the interface between the flow loop and the hierarchical manifold distributor. The manifold distributor distributes the working fluid from a single inlet to each unit of the microchannel heat sink and collects the outgoing working fluid and guides it to a single outlet. PCB provides measurement and power supply interface for the heaters and sensors on the cooling chip.

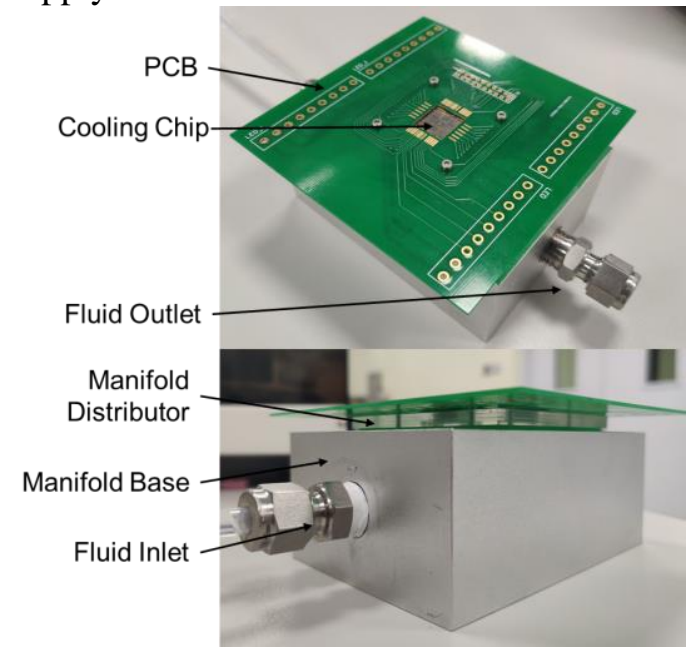

Fig.2: Schematic diagram of the test vehicle. 
The flow loop used in the experiment is shown in Figure 3. The background pressure of the flow loop is set by the surge tank. The working fluid is circulated by the magnetic drive gear pump (Oerlik, MG213XK/DC24W1) and is heated after flowing though the test section. The heated liquid passes through the filter to filter out the particles and enters the integrated microchannel heat exchanger (SS-0010WT-BS). Convection heat transfer is conducted between the fluid and the cooling water from the constant temperature bath (Tianling, DC-0506). Finally, the working fluid returns to the gear pump to complete the circulation. A series of sensors are installed on the flow loop. The temperature sensor (three-wire armored platinum resistance, PT100) is used to measure the inlet and outlet temperatures of the test section. The test section inlet and outlet pressure is measured by the pressure sensor (Legg meter, SMP136) and the pressure difference between the inlet and outlet is measured by a differential pressure sensor (Omega, PX2300-50BDI). The flow sensor (Omega, FTB601B) is applied to measure the volumetric flow rate. The data recorded by the sensor is collected by the PLC controller (Horner, x14-106), and the controller is connected to the LabVIEW platform for data reading and storage using Modbus protocol.

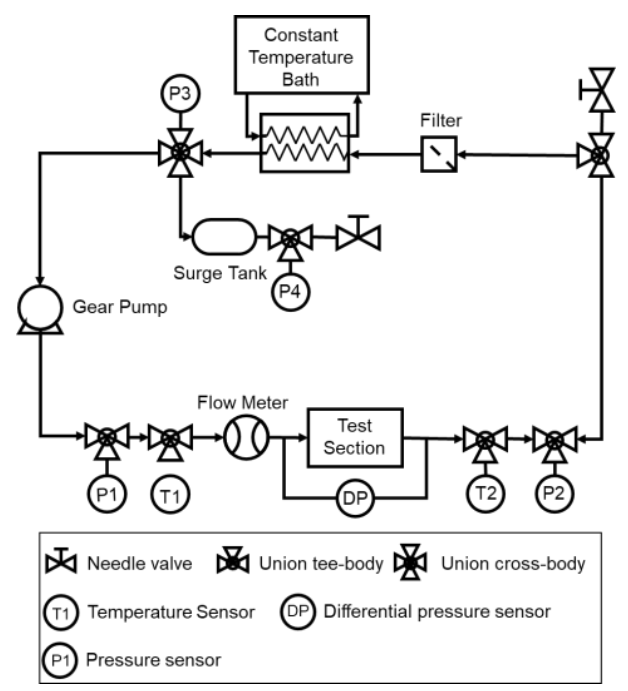

Fig.3: Schematic diagram of the flow loop.

\section{Results and discussion}

For the single-phase flow and heat transfer experiment of the manifold microchannels, the hydraulic and thermal performance in microchannels with different depths were systematically tested under the inlet flow rate from 200 to 400 $\mathrm{mL} / \mathrm{min}$. DI water and HFE-7100 were chosen as the working fluids.

\subsection{Pressure Drop}

The relationship between the pressure drop and the base heat flux in the 150 - $\mu \mathrm{m}$-deep microchannel at different inlet flow rates is shown in Figure 4. According to Newton's law of internal friction, the pressure drop of the laminar flow can be calculated via $\Delta p=32 \mu V L / D_{h}{ }^{2}$, where $\mu$ is the dynamic viscosity, $V$ is the flow velocity, $L$ is the flow length, and $D_{h}$ is the hydraulic diameter of the channel. Thus, the pressure drop of the channel is proportional to the inlet velocity. The larger flow rate, the higher pressure drop along the microchannels. As the heat flux increases, temperature rise in the microchannel will affects the viscosity of the working fluid. Here, water viscosity decreases as the temperature increases, therefore, the pressure drop gradually decreases as the base heat flux increases. Figure 4 also compares the pressure drop of microchannel with different depths at the inlet flow rate $\mathrm{f}=200 \mathrm{~mL} / \mathrm{min}$. As the single-phase flow pressure drop is inversely proportional to $D_{h}{ }^{2}$, microchannel with small hydraulic diameter suggests larger pressure drop during single-phase flow. For the microchannel of $40 \mu \mathrm{m}, 150 \mu \mathrm{m}$ and $300 \mu \mathrm{m}$ depth, the corresponding maximum pressure drop is $44.375 \mathrm{kPa}$, $15.25 \mathrm{kPa}$ and $11.8125 \mathrm{kPa}$, respectively. The comparison of simulation and experimental results in $150-\mu \mathrm{m}$-deep 
microchannel is shown in Figure 5. The pressure drop of the experimental results is slightly larger than that of the simulation value. The discrepancy is caused by the geometry of experimental vehicle. Besides the viscosity loss in the channel, the pressure drop measured by the experiment also includes contraction into and expansion out of the contraction/expansion resistances in the manifold [9].

Since the pressure drop of microchannel is closely related to the dynamic viscosity of working fluid. Pressure drop of the channel varies when changing the working fluid. The dynamic viscosity of HFE-7100 is $6.2 \times 10^{-4} \mathrm{~Pa} \cdot \mathrm{s}$, while that of water is $8.9 \times 10^{-4} \mathrm{~Pa} \cdot \mathrm{s}$ [10]. Therefore, the pressure drop can be significantly reduced using HFE-7100 as the working fluid at the same flow speed. However, due to the difference in density $\left(1455 \mathrm{~kg} / \mathrm{m}^{3}\right.$ for HFE-7100 and $1000 \mathrm{~kg} / \mathrm{m}^{3}$ for water), the channel Reynolds number with HFE-7100 is higher at the same inlet flow rate. The experimental results in Figure 6 also show that the pressure drop of the channel with HFE-7100 is significantly greater than that with water.

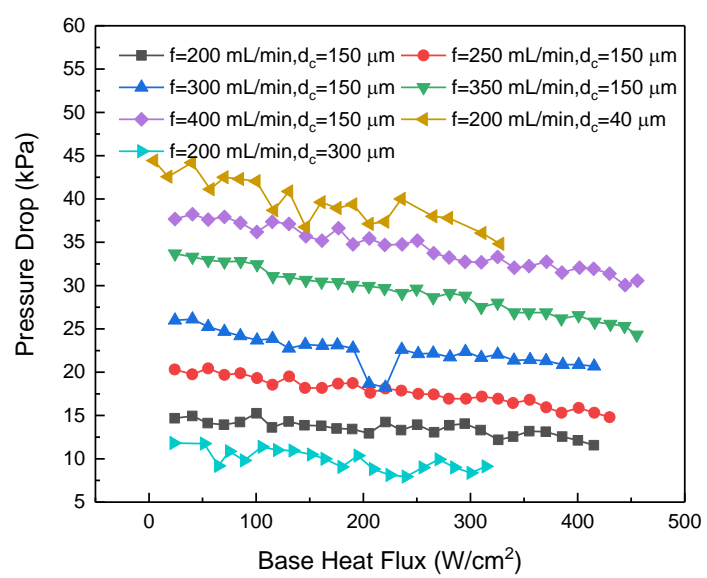

Fig. 4: Single phase pressure drop between inlet and outlet using water as working fluid.

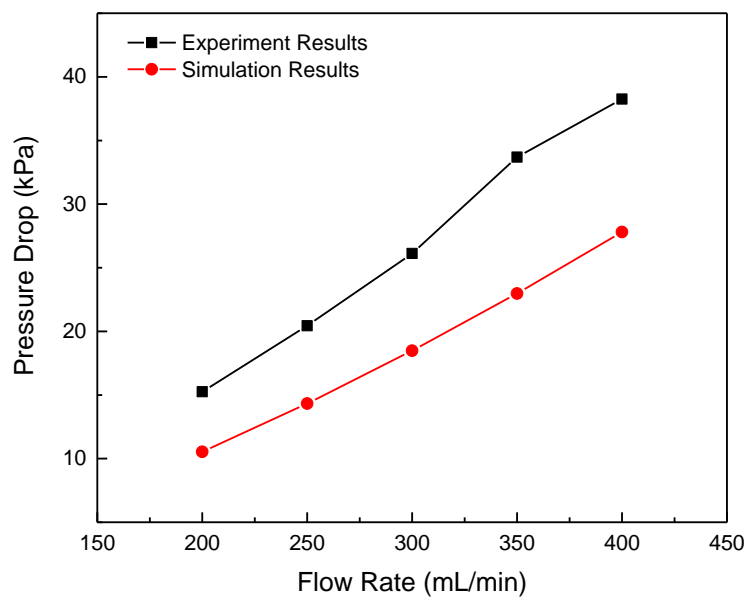

Fig. 5: Pressure drop in 150- $\mu$ m-deep microchannel as function of flow rate. 


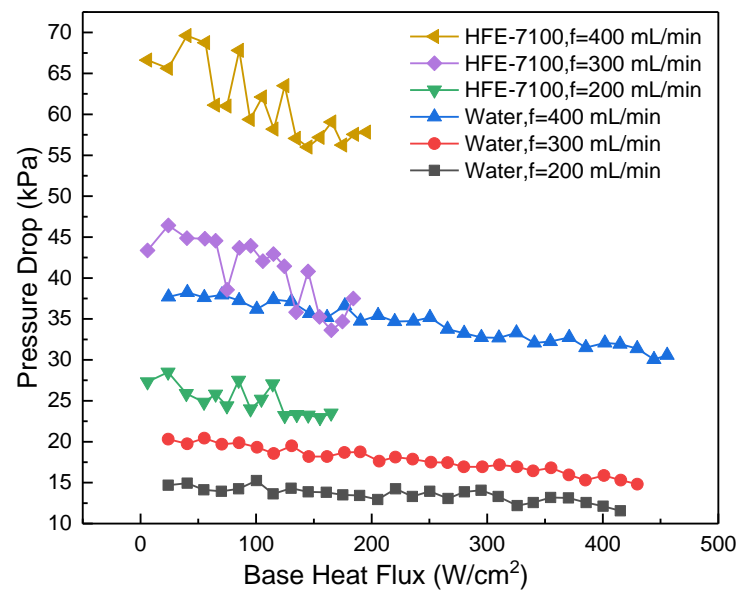

Fig. 6: Pressure drop of different working fluids for different flow rates.

\subsection{Heat Transfer Coefficient}

To evaluate the heat transfer performance of the manifold microchannel heat sinks, heat transfer coefficient under different working conditions were calculated. In this work, the wall heat transfer coefficient is calculated by $h_{\text {wall }}=Q_{\text {net }} / \eta_{0} A_{\text {wet }}\left(T_{\text {base, avg }}-T_{f l, \text { ref }}\right)$, where $Q_{\text {net }}$ is the total heat input to the cooling chip, $A_{\text {wet }}$ is the wetted area, $T_{\text {base avg }}$ and $T_{f l, r e f}$ are the average base temperature and the reference temperature of the working fluid (defined as the average value of the fluid inlet and outlet temperature). $\eta_{0}$ is the overall surface efficiency and is calculated from $\eta_{0}=1-N A_{f}\left(1-\eta_{f}\right) / A_{\text {wet }}$, where the fin efficiency $\eta_{f}$ can be calculated through $\eta_{f}=\tanh \left(m d_{c}\right) / m d_{c}$ and $m=\sqrt{\frac{2 h_{\text {wall }}}{k_{S i} w_{f}}}$.

Figure 7 demonstrates the heat transfer coefficient as a function of the base heat flux under different flow rate and microchannel depths. In general, the heat transfer coefficient slightly decreases as the base heat flux increases. This is mainly caused by the insufficient cooling of the working fluid under high heat flux conditions $\left(\dot{Q}>200 \mathrm{~W} / \mathrm{cm}^{2}\right)$. For microchannel with the same geometry, for example, $d_{c}=150 \mu \mathrm{m}$, the heat transfer coefficient gradually increases as the inlet flow rate increases under the same base heat flux. To study the effect of channel depth on heat transfer coefficient, three microchannels with the same inlet flow rate were studied (as illustrated in Figure 7). It can be seen that the heat transfer coefficient of the microchannel with $40 \mu \mathrm{m}$ depth is the highest, that of the microchannel with the $150 \mu \mathrm{m}$ depth is the second, and that of the 300- $\mu \mathrm{m}$-deep microchannel is the smallest. In particular, when the inlet flow rate $\mathrm{f}=200 \mathrm{ml} / \mathrm{min}$, the corresponding mass fluxes for microchannels with the depth of $40 \mu \mathrm{m}, 150 \mu \mathrm{m}$ and $300 \mu \mathrm{m}$ are $2531.8 \mathrm{~kg} / \mathrm{m}^{2} \mathrm{~s}, 675.2$ $\mathrm{kg} / \mathrm{m}^{2} \mathrm{~s}$ and $337.6 \mathrm{~kg} / \mathrm{m}^{2} \mathrm{~s}$, respectively. To further investigate the dependence of heat transfer coefficient on flow rate, channel geometry, and working fluids, numerical simulation was performed with the laminar flow and heat transfer modules of COMSOL Multiphysics 5.4 on a Dell Precision T7820 workstation operated with Ubuntu 17.10. By calculating the maximum heat transfer coefficient at each inlet flow rate (see Figure 8), it is noted that the heat transfer coefficient increases linearly with the inlet flow rate for each working condition. Simulation results confirm the underlying heat and mass transport mechanism and show good agreement with the experiments. 


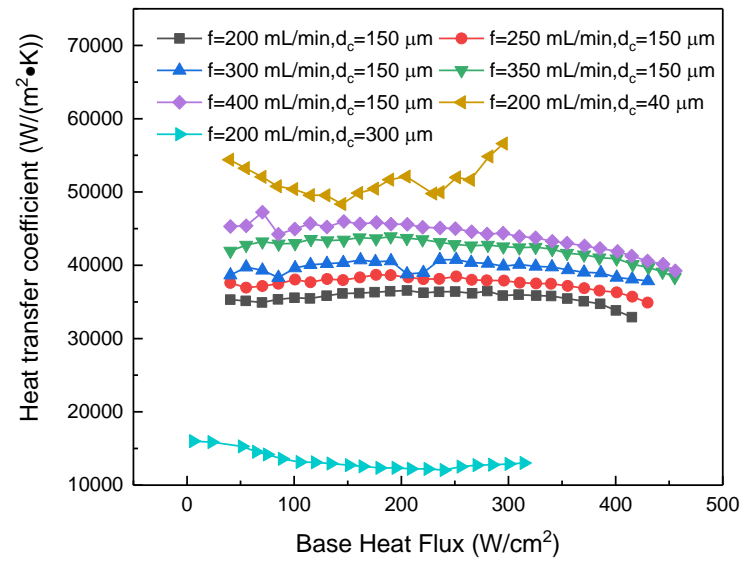

Fig. 7: Heat transfer coefficient to base heat flux with different flow rate and channel geometry.

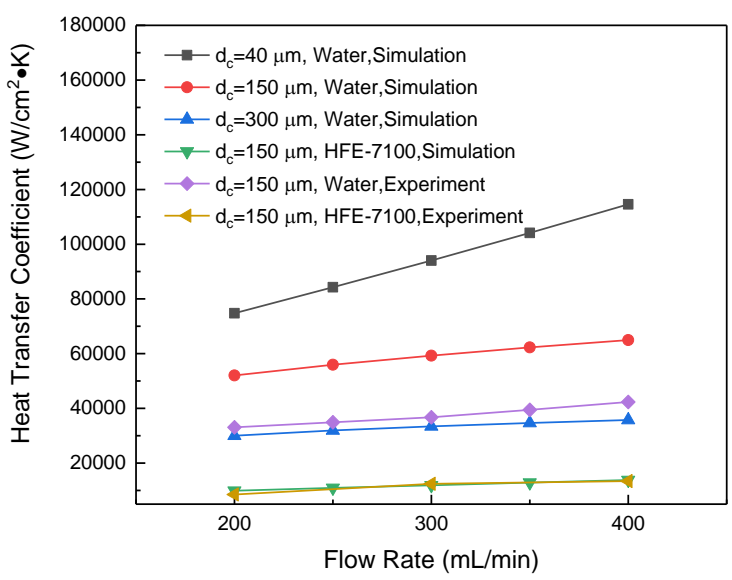

Fig. 8: Heat transfer coefficient to flow rate with different working fluids and channel geometry.

\subsection{Effective thermal Resistance}

The effective thermal resistance of the cooling chip in this work is calculated by $R_{\text {eff }}=A_{b}\left(T_{\text {chip,avg }}-T_{f l, \text { in }}\right) / Q_{\text {net }}$, where $A_{b}$ is the base area, $T_{\text {chip,avg }}$ is the average chip temperature and $T_{f l, \text { in }}$ the fluid inlet temperature.

Figure 9 shows the experimental results of the effective thermal resistance using water as the working fluid. For the single-phase flow heat transfer, the thermal resistance of the cooling chip is mainly composed of the base conduction resistance and the convective heat transfer resistance on the wall. When the same chip is deployed, the influence of conduction thermal resistance (mainly determined by base thickness) and heat transfer area on the effective thermal resistance can be ignored. As shown in Figure 9, the distribution of effective thermal resistance corresponds to the change of wall heat transfer coefficient. The higher the inlet flow rate, the smaller the effective thermal resistance of the cooling chip. The effective thermal resistance of the microchannel heat sink with water is much less than that with HFE-7100 as illustrated in Figure 10.

The relationship between the effective thermal resistance and base heat flux in microchannel of different depths is also shown in Figure 9. According to the convection heat transfer theory, the heat flux $q=h A \Delta T$, therefore the effective thermal resistance of the cooling chip depends on the heat transfer coefficient $h$ and the heat transfer area $A$. It is noted that the heat transfer coefficient decreases with the increase of channel depth at the same inlet flow rate. On the contrary, the deeper the channel, the larger the heat transfer area. Therefore, on the common effect of these two 
factors, the effective thermal resistance is minimal for $150-\mu \mathrm{m}$-deep microchannel, moderate in $300-\mu \mathrm{m}$-deep microchannel, and maximal on 40- $\mu \mathrm{m}$-deep microchannel. It should be noted that the base conduction thermal resistance resistance for microchannels with $40 \mu \mathrm{m}, 150 \mu \mathrm{m}$, and $300 \mu \mathrm{m}$ in depth is $3.96 \times 10^{-6} \mathrm{~m}^{2} \cdot \mathrm{K} / \mathrm{W}, 3.12 \times 10^{-6} \mathrm{~m}^{2} \cdot \mathrm{K} / \mathrm{W}$ $3.12 \times 10^{-6} \mathrm{~m}^{2} \cdot \mathrm{K} / \mathrm{W}$ and $1.96 \times 10^{-6} \mathrm{~m}^{2} \cdot \mathrm{K} / \mathrm{W}$, accounting for $15.6 \%, 20.8 \%$ and $11.1 \%$ of the total thermal resistance, respectively.

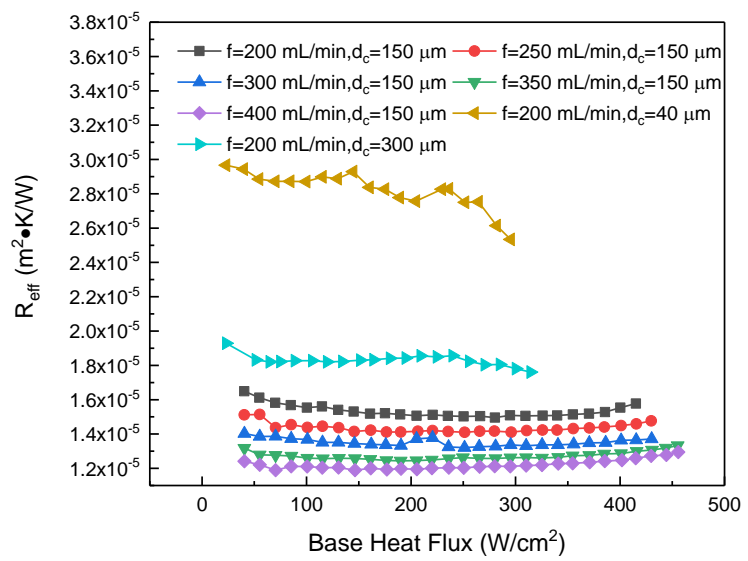

Fig. 9: Effective thermal resistance in microchannel of different depths using water as working fluid.

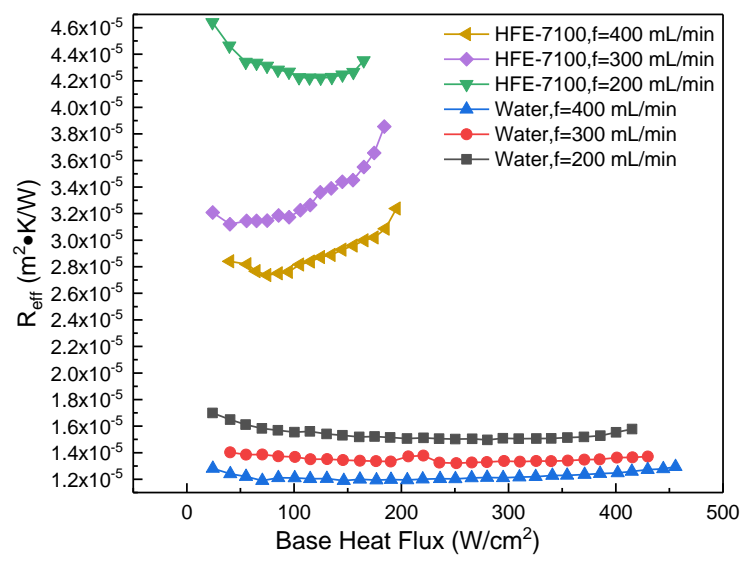

Fig. 10: Effective thermal resistance of different working fluids for different flow rates.

\section{Conclusion}

In summary, an on-chip hierarchical manifold microchannel heat sink array is designed and fabricated, and its flow and heat transfer characteristics are simulated and experimentally studied in detailed. The main conclusions are summarized as follows:

(1) For the same microchannel, the pressure drop of the manifold microchannel increases linearly with the inlet flow rate. The pressure drop is inversely proportional to the channel depth at the same flow rates. Due to the difference of flow velocity caused by the density of working fluid, the pressure drop for water is smaller though the dynamic viscosity of HFE-7100 is smaller than that of water.

(2) The wall heat transfer coefficient of the manifold microchannel increases linearly with the inlet flow rate. For the same flow rate, the heat transfer coefficient is inversely proportional to the aspect ratio. For the single-phase flow, the heat transfer coefficient of water is much higher than that of HFE-7100 due to the difference of thermal properties. 
(3) The distribution of the effective thermal resistance in the same microchannel corresponds to the wall heat transfer coefficient, and the effective thermal resistance decreases with the increase of inlet flow rate. The thermal resistance of the microchannel with $150 \mu \mathrm{m}$ depth is the smallest, followed by $300 \mu \mathrm{m}$, and the thermal resistance is the largest when the depth is $40 \mu \mathrm{m}$. Under the same working conditions, the effective thermal resistance of water is far less than that of HFE-7100.

\section{Acknowledgements}

This work was supported by the National Natural Science Foundation of China under the Grant Agreement 51806232 and the National Defense Scientific Research Project under the Grant Agreement JCKY2017203C043.

\section{References}

[1] D. B. Tuckerman and R. F. W. Pease, "High-performance heat sinking for VLSI," IEEE Electron Device Lett., vol. 2, no. 5, pp. 126-129, May 1981, doi: 10.1109/EDL.1981.25367.

[2] G. M. Harpole and J. E. Eninger, "Micro-channel heat exchanger optimization," in 1991 Proceedings, Seventh IEEE Semiconductor Thermal Measurement and Management Symposium, Phoenix, AZ, USA, 1991, pp. 59-63, doi: 10.1109/STHERM.1991.152913.

[3] J. C. Harley, Y. Huang, H. H. Bau, and J. N. Zemel, "Gas flow in micro-channels," J. Fluid Mech., vol. 284, pp. 257274, Feb. 1995, doi: 10.1017/S0022112095000358.

[4] R. R. Reston and E. S. Kolesar, "Silicon-micromachined gas chromatography system used to separate and detect ammonia and nitrogen dioxide. I. Design, fabrication, and integration of the gas chromatography system," $J$. Microelectromechanical Syst., vol. 3, no. 4, pp. 134-146, Dec. 1994, doi: 10.1109/84.338634.

[5] A. Ijam and R. Saidur, "Nanofluid as a coolant for electronic devices (cooling of electronic devices)," Appl. Therm. Eng., vol. 32, pp. 76-82, Jan. 2012, doi: 10.1016/j.applthermaleng.2011.08.032.

[6] Y. H. Kim, W. C. Chun, J. T. Kim, B. C. Pak, and B. J. Baek, "Forced air cooling by using manifold microchannel heat sinks," KSME Int. J., vol. 12, no. 4, pp. 709-718, Jul. 1998, doi: 10.1007/BF02945732.

[7] W. Escher, B. Michel, and D. Poulikakos, "A novel high performance, ultra thin heat sink for electronics," Int. J. Heat Fluid Flow, vol. 31, no. 4, pp. 586-598, Aug. 2010, doi: 10.1016/j.ijheatfluidflow.2010.03.001.

[8] R. S. Andhare, A. Shooshtari, S. V. Dessiatoun, and M. M. Ohadi, "Heat transfer and pressure drop characteristics of a flat plate manifold microchannel heat exchanger in counter flow configuration," Appl. Therm. Eng., vol. 96, pp. 178189, Mar. 2016, doi: 10.1016/j.applthermaleng.2015.10.133.

[9] K. P. Drummond, D. Back, M. D. Sinanis, D. B. Janes, D. Peroulis, J. A. Weibel, and S V. Garimella, "A hierarchical manifold microchannel heat sink array for high-heat-flux two-phase cooling of electronics," Int. J. Heat Mass Transf., vol. 117, pp. 319-330, Feb. 2018, doi: 10.1016/j.ijheatmasstransfer.2017.10.015.

[10]E. Cetegen, "Force fed microchannel high heat flux cooling utilizing microgrooved surfaces," 2010. 